\title{
Proximity to Service Providers and Service Utilization among Welfare Recipients: The Interaction of Place and Race
}

\author{
Scott W. Allard \\ Richard M. Tolman \\ Daniel Rosen
}

\begin{abstract}
Currently, welfare programs coordinate a range of services to support work among welfare recipients and help them overcome barriers to employment. This paper considers the relationship between spatial proximity to and utilization of support services among welfare recipients. Accessibility of mental health and substance abuse service providers among welfare recipients is examined in the three-county Detroit metropolitan area and the relationship between mental health service accessibility and mental health service utilization among welfare recipients considered. Not only does access to service providers vary significantly across the metropolitan area by race and place, but these analyses reveal that greater spatial proximity to service providers increases the probability that welfare recipients will receive services. When controlling for access to providers and individual-level characteristics, we also find that African American welfare recipients are about half as likely to use mental health services as white recipients. (C) 2003 by the Association for Public Policy Analysis and Management.
\end{abstract}

\section{INTRODUCTION}

Increasing evidence indicates that significant numbers of welfare recipients experience barriers to employment (Danziger et al., 2000; GAO, 2001; Zedlewski and Alderson, 2001). For instance, some human capital factors-such as low job skills, little work experience, or low levels of education — can inhibit work activity. Physical limitations, mental health problems, substance use or abuse, and domestic violence can be significant obstacles to work activity (Danziger et al., 2000). Job accessibility and proximity to employment opportunities have also been found to affect whether welfare recipients find work and exit welfare (Allard and Danziger, 2003). As a result, policymakers and program managers operating in a work-first environment will continue to seek strategies to provide a range of support services that can help those remaining on welfare overcome these common barriers to employment.

Research indicates that a number of factors determine whether low-income or atrisk populations use available support services. Inadequate linkages between service providers in different program areas, inefficient administration, lack of cultural competency, and insufficient outreach by service providers have been identified as factors shaping social service utilization rates among low-income populations

Manuscript received April 2002; out for review April 2002; review completed July 2002; revision completed November 2002; accepted March 2003.

Journal of Policy Analysis and Management, Vol. 22, No. 4, 599-613 (2003)

(C) 2003 by the Association for Public Policy Analysis and Management

Published by Wiley Periodicals, Inc. Published online in Wiley InterScience (www.interscience.wiley.com) DOI: $10.1002 /$ pam.10157 
(Nightingale, 2001; University of Wisconsin, 1999; Wynn, 1995). Service utilization rates have also been found to vary across different race and class groups (Alvidrez, 1999; Snowden, 1999). The relationship between spatial proximity to support services and service utilization among welfare recipients, however, has received relatively little attention.

This paper reports an examination of the effect of individual-level characteristics and spatial proximity to social service providers on service utilization rates among women receiving welfare. The hypothesis is that, controlling for individual-level characteristics, spatial proximity to relevant social service providers will correlate positively with rate of service utilization. To test this hypothesis, we examine spatial access to mental health and substance abuse treatment, an important subset of support services, among welfare recipients in the three-county Detroit metropolitan area. We then consider the relationship between mental health service accessibility and mental health service utilization rates among welfare recipients.

Understanding the linkage between spatial access to service providers and service utilization among welfare recipients has a number of policy-relevant implications. More than half of all TANF expenditures today finance support services for welfare recipients, with increasing reliance upon non-governmental organizations for the delivery of those services (GAO, 2001, 2002a; HHS, 2002). Moreover, mental health and substance abuse services are particularly important components of welfare-to-work programs that address barriers to employment among welfare recipients. Finally, from a research perspective, clarifying the relationship between access to support services and use of support services casts insight onto the interaction of individual- and place-level factors that shape welfare-to-work program outcomes.

\section{SOCIAL SERVICE UTILIZATION AMONG WELFARE MOTHERS}

The literature on service utilization has identified a number of administrative factors that affect service receipt among welfare recipients and other low-income atrisk populations. The complexity of eligibility determinations (GAO, 2000), emphasis on job search over utilization of support services (Klerman et al., 2000; Nightingale, 2001; Wynn, 1995), and lack of adequate information about the range of social services available (GAO, 2002b; Nightingale, 2001; University of Wisconsin, 1999) all affect service utilization among low-income individuals. In addition, language, racial, and cultural barriers between clients and service providers are commonly cited factors that discourage service utilization among low-income individuals (Bhugra, 2002; Whaley, 2001; Williams et al., 2001).

Particularly relevant to this study are a number of individual-level factors that affect whether welfare recipients receive, specifically, substance abuse and mental health treatment services. Higher levels of educational attainment and income have been found to be correlated with higher rates of mental health service utilization (Howard et al., 1996; Sherbourne, Dwight-Johnson, and Klap, 2001). Even after controlling for income and education, however, African Americans appear less likely to use mental health services than whites. Racial differences in service utilization have been explained in part by beliefs among African Americans that mental health problems should be addressed within the family (Alvidrez, 1999) and by higher thresholds for help-seeking behavior among African Americans (Snowden, 1999; Swartz et al., 1998). Lack of personal efficacy, concerns over the burden of administrative procedures, and mistrust of service providers, have all been found to lead to lower utilization rates (Richman and Stagner, 1986). Preg- 
nancy or child care responsibility can affect utilization of substance and mental health services because women may not seek treatment for fear of losing custody of their children or because arranging child care is difficult (Bass and Jackson, 1997; Comfort, Loverro, and Kaltenbach, 2000; Howell and Chasnoff, 1999; Nelson-Zlupko, Kauffman, and Dore, 1995; Wobie et al., 1997). Finally, costs associated with treatment and lack of insurance coverage may also reduce mental health service utilization rates (Derr, Hill, and Pavetti, 2000; Melfi, Croghan, and Hanna, 1999; SAMHSA, 1999).

In addition to these administrative and individual-level factors, we hypothesize that service utilization among welfare recipients is likely to be affected by the spatial accessibility of service providers. ${ }^{1}$ Spatial access or proximity to service providers can affect service utilization rates among welfare recipients in a number of different ways. Longer distance implies more difficult commutes, particularly for welfare recipients who may have less access to automobile transportation than the general population. Given the complex commutes to work, child care, and welfare program offices that welfare recipients make daily, more distant service providers will be more difficult to access. Since agencies and organizations are likely to be better connected to service providers in their immediate area, caseworkers may not make provider referrals outside that immediate area. Similarly, welfare recipients farther from a service provider would be expected to have less information about that provider and thus less likely to seek services from that provider.

\section{DATA AND METHODOLOGY}

To examine the spatial accessibility of support services among welfare recipients, we focused on mental health and substance abuse services. Mounting evidence suggests that welfare recipients have significantly higher rates of psychiatric disorders than their non-welfare counterparts (Danziger et al., 2000), and that substance abuse is at least as prevalent among welfare recipients as non-recipients (Jayakody, Danziger, and Pollack, 2000; Jayakody and Stauffer, 2000). When present, mental health disorders and/or substance abuse problems affect the employment outcomes of welfare recipients (Danziger et al., 2000). ${ }^{2}$ As a result, support services to address mental health and substance barriers to employment have become common components of welfare-to-work strategies and are intended to improve the economic outcome of welfare recipients experiencing those barriers (Jayakody, Danziger, and Pollack, 2000; Metsch et al., 1999).

We link survey responses about service utilization among welfare recipients in the Detroit metropolitan area in 1999 with information about access to mental health and substance abuse service providers in 2000 to create a unique data set. We draw our individual-level survey data from the Mothers' Well-Being Study (MWS), a 1999 study developed to examine the individual, family, and neighborhood factors that influence low-income women as they seek and retain employment. This random sample of 668

\footnotetext{
${ }^{1}$ Research on hospitalization rates and health care service utilization indicates that as distance between a facility and a resident increases, the likelihood of receiving services at that facility decreases, see Goodman et al. (1997) and Nemet and Bailey (2000).

${ }^{2}$ Danziger et al. (2000) found that depression, but not post-traumatic stress disorder or generalized anxiety disorder, was associated with a lower probability of employment among women who had been recent welfare recipients. The authors also found that drug dependence, but not alcohol dependence, marginally reduced employment outcomes.
} 
welfare recipients in the Detroit metro area asked respondents about recent employment, welfare receipt, transportation, residential location, mental health conditions, alcohol and substance use, domestic violence, and the use of mental health services. ${ }^{3}$ Information was geocoded on the residential location of respondents to indicate the census tract of residence. When properly weighted, the MWS data are generalizable to the welfare caseload in the three-county Detroit metropolitan area.

Data on the location of mental health and substance abuse service providers in the Detroit metropolitan area in 2000 were drawn from provider lists maintained by the United Way Community Services of southeastern Michigan (UWCS) and the Substance Abuse and Mental Health Service Administration (SAMHSA) in the Department of Health and Human Services. ${ }^{4}$ Phone interviews verified whether each provider offered mental health or substance abuse services to low-income women and whether the provider offered outpatient services in these areas to low-income women. A provider was classified as "serving low-income women" when staff reported treating low-income women, accepting Medicaid, or having a sliding-scale fee structure in place for low-income women. Thus, our Detroit Service Provider Database (DSPD) reflects the universe of mental health and substance abuse providers in the Detroit metro area, as well as those providers most likely to treat welfare recipients. From the street addresses listed in the DSPD, the census tract location of each provider was identified.

To capture the proximity of welfare recipients to outpatient mental health and substance abuse service providers, information from the DSPD was used to create five different service provider accessibility measures: Access to All Outpatient Mental Health and Substance Abuse Service Providers Serving Low-income Women in 2000 within 1.5 miles; Access to Outpatient Mental Health Service Providers Serving Low-income Women in 2000 within 1.5 miles; Access to Outpatient Mental Health Service Providers Serving Low-income Women in 2000 within 3 miles; Access to Outpatient Substance Abuse Service Providers Serving Low-income Women in 2000 within 1.5 miles; and, Access to Outpatient Substance Abuse Service Providers Serving Low-income Women in 2000 within 3 miles. The first access measure includes all service providers offering mental health or substance abuse treatment that treat low-income women, a liberal definition of service accessibility. Our remaining four access scores consider proximity to all service providers offering outpatient mental health or substance abuse treatment specifically to low-income women at 1.5 - and 3-mile radii. The decision to use 1.5-mile and 3-mile radii was based on conversations with county social service administrators in the Detroit metro area, which indicated that welfare recipients generally would not be expected to commute more than 1 or 2 miles to a social service provider.

Access scores were created for each respondent in the MWS through a two-step process. Using the centroid coordinates of each residential tract and each tract containing a service provider, the number of mental health or substance abuse service providers was calculated for a particular criterion that fell within 1.5 miles and 3 miles of each census tract in the metropolitan area. These provider counts represent raw

3 The survey sample was selected from administrative records provided by the State of Michigan Family Independence Agency (FIA). Included were all those who were receiving welfare in September 1998 in Wayne, Oakland, and Macomb Counties. Using information from the administrative records, the sample was limited to African American and white women ages 18 to 54. Non-citizen, non-English speaking, and two parent households were excluded. Of the 859 women randomly selected from FIA administrative records who met these criteria, 668 were interviewed by telephone, for an overall response rate of nearly 78 percent.

${ }^{4}$ We received approval from the University of Michigan Institutional Review Board to link these two databases together. 


\section{Proximity and Service Utilization among Welfare Recipients / 603}

access scores of service accessibility. Each census tract's raw access score was then divided by the overall metropolitan mean tract raw access score to create a weighted access measure that could be more readily compared across individuals. A service provider access score above 0 indicates the presence of a provider within 1.5 miles of the tract centroid and a score of 0 indicates that there are no providers within 1.5 miles of the tract centroid. Further, a welfare recipient living in a tract with an access score of 1.10 resides near 10 percent more providers than does the resident of the tract with the metropolitan mean access score; a recipient living in a tract with an access score of 0.90 resides near 10 percent fewer providers than a resident of the mean metropolitan tract.

It is possible that service providers may locate nearer areas where potential clients are most likely to reside. Under these conditions, any observed relationships between proximity and utilization simply may be capturing providers' unobserved locational decisions. Even if providers purposively locate near potential client pools for unobservable reasons, however, such realities reinforce the importance of spatial accessibility and the adverse effect of poor service accessibility. Such endogeneity would complicate interpretation of regression coefficients relating to service accessibility, more than it would compromise the measurement of the intensity of the relationship between access and service utilization. ${ }^{5}$

We believe our findings based on the accessibility of mental health and substance abuse services in Detroit are generalizable to other settings. Detroit is typical of many rust-belt industrial cities, with its declining central city, racially diverse but residentially segregated population, high-poverty central city, and low-poverty suburban ring. Because the MWS should accurately reflect the characteristics of those individuals currently receiving welfare, our data provide a reasonable sense of the challenges that state welfare-to-work programs will continue to face in coming years. We believe issues of spatial accessibility within mental health and substance abuse service provision pose challenges similar to those in other service settings.

\section{SPATIAL DISTRIBUTION OF SUPPORT SERVICES IN DETROIT}

Table 1 reports weighted sample means and frequencies. Roughly 80 percent of MWS respondents were African American and more than three-quarters of MWS respondents lived in the city of Detroit. ${ }^{6}$ Nearly 40 percent of respondents did not have a high school degree. On average, respondents had received welfare in about two-thirds of the 12 months previous and had worked in about half of the 12 months prior to the survey. Consistent with existing research, 39.2 percent of MWS respondents met criteria for at least one mental health disorder in the 12 months before the survey and 6.7 percent of respondents indicated substance or alcohol abuse in the 12

5 Also, it is possible that welfare recipients most likely to need or seek services will choose to live in neighborhoods with a high degree of access to service providers. We believe it is unlikely that welfare recipients would make residential choices based on outpatient services they may utilize for a brief period of time, particularly since proximity to employment, family, and child care will be much more prominent considerations shaping residential choice. To our knowledge, mental health and substance abuse service providers in the Detroit metropolitan area were not conducting spatial accessibility assessments that would shape our access measures or findings in any manner.

6 These percentages are consistent with administrative data from February 2000, where 75.8 percent of welfare recipients in the three-county area were non-white minorities and 75.5 percent of welfare recipients in the area lived in the city of Detroit, see Allard (2002). Respondents were asked, "Which of the items listed do you feel best describes your race?' and were given choices between white, African American, Native American, Asian American, or "other." 
604 / Proximity and Service Utilization among Welfare Recipients

Table 1. Variable means and definitions.

\begin{tabular}{lc}
\hline Characteristic of MWS Respondent & Weighted \% \\
\hline African American & 80.5 \\
White & 19.5 \\
Percentage with Mental Health Status Score Below National Mean & 38.6 \\
Any Mental Health Disorder in Previous 12 Months & 39.2 \\
Any Substance or Alcohol Abuse in Previos 12 Months & 6.7 \\
Any Outpatient Mental Health Service Utilization in Previous 12 Months & 7.2 \\
Resident of Macomb County & 4.5 \\
Resident of Oakland County & 5.8 \\
Resident of Suburban Wayne County & 11.4 \\
Resident of the City of Detroit & 77.7 \\
Less Than a High School Degree & 39.7 \\
Have Child(ren) Under 5 Years in Household & 63.3 \\
Have Regular Use or Access to Automobile & 60.1 \\
18 to 24 Years of Age & 24.2 \\
25 to 34 Years of Age & 45.1 \\
35 or More Years of Age & 30.6 \\
Percentage of Months on Welfare in 12 Months Prior to Interview & 67.8 \\
Percentage of Months Worked in 12 Months Prior to Interview & 54.9 \\
Poverty Rate in Tract, 1990 Census & 32.5 \\
\hline
\end{tabular}

Note: Reported means and percentages are weighted using the MWS sample survey weights.

Sources: MWS Survey; Detroit Service Provider Database; 1990 Census of the Population.

months before the survey. ${ }^{7}$ In the 12 months prior to the MWS survey, 7.2 percent of all respondents reported receiving outpatient mental health services.

Table 2 examines how MWS respondents' proximity to providers varies by race and place across five different provider accessibility measures. The top panel reflects access across whites and African Americans in the MWS; the bottom panels reflect access to service providers in each jurisdiction and by race within each jurisdiction. When looking at access to all service providers treating low-income women (column 1), African Americans in the MWS tend to reside in areas with greater access than whites (1.538 versus 0.940$)$, with columns 4 and 5 indicating that such differences are driven by greater access to substance abuse service providers among African Americans in the MWS.

Across all five measures of service accessibility, MWS respondents living in the city of Detroit have greater access to service providers than many respondents living in nearby suburban areas. For example, respondents in Detroit have access to over 90 percent more mental health and substance abuse service providers than respondents in nearby suburban Wayne County and almost 60 percent more providers than respondents in Macomb County (column 1, 1.530 versus 0.583 and 0.961, respectively). Welfare recipients in Oakland County, however, have access to roughly two to three times as much access to mental health and substance abuse providers treating low-income women than recipients in Wayne or Macomb counties (column 1, 1.976 versus 0.583 and 0.961 , respectively).

7 The MWS measures a broad range of affective, anxiety, and substance abuse disorders. The MWS used the World Health Organization's (WHO) Composite International Diagnostic Interview (CIDI), a widely used psychiatric diagnostic instrument designed for use by trained interviewers who are not clinicians. The CIDI is used in general population surveys to assess psychiatric disorders and is supported by extensive CIDI Field Trial data on cross-national reliability and validity (Wittchen, 1994). 
Proximity and Service Utilization among Welfare Recipients / 605

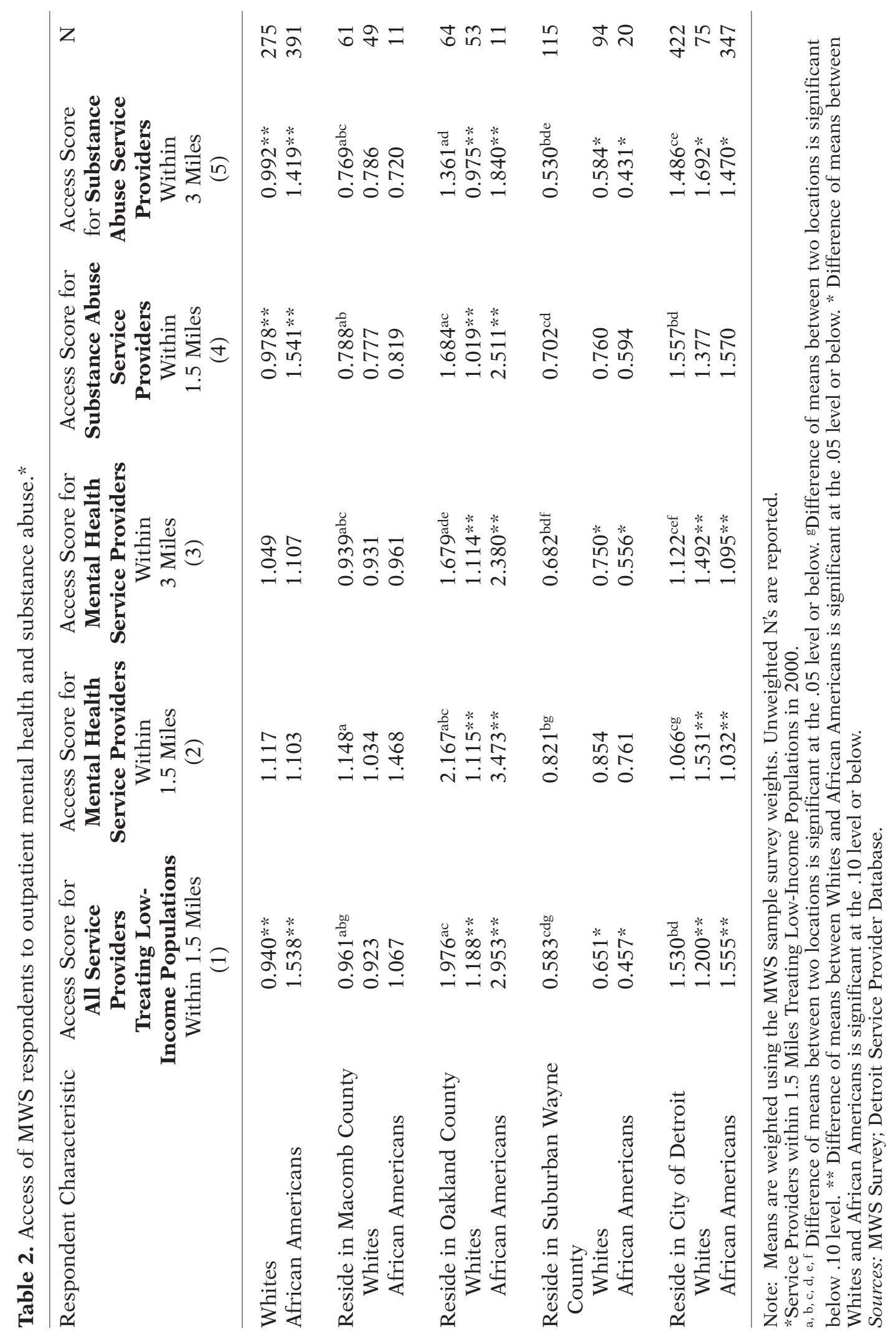


Figure 1 maps these mean tract access scores, providing a visualization of access to mental health and substance abuse service providers treating low-income women. White areas indicate tracts with no providers inside a 1.5-mile radius, the darker areas reflect tracts with greater levels of service accessibility. Consistent with the findings in Table 2, Figure 1 shows that the areas with the greatest access to service providers are located near the city of Detroit and urbanized portions of Oakland County. On the other hand, Figure 1 also shows that many suburban residential areas have few or no providers treating low-income populations within a 1.5mile radius.

When looking at access to mental health and substance abuse service providers separately, these spatial patterns generally persist. Respondents living in Detroit have access to more mental health service providers than respondents in suburban Wayne both at a 1.5-mile and 3-mile radius (Table2, column 2 and 3), but have access to fewer mental health service providers than welfare recipients in Oakland County. While respondents in the city of Detroit and in Oakland County have comparable levels of access to substance abuse providers at 1.5- and 3-mile radii, respondents in these portions of the metropolitan area have much greater access to substance abuse services than respondents living in suburban Wayne and Macomb Counties (columns 4 and 5). Table 2 also indicates that access to service providers between whites and African Americans in the MWS has a distinct geographic component. White MWS respondents in Detroit have access to about 50 percent more mental health service providers than African Americans in Detroit (column 2, 1.531 versus 1.032, respectively). Very similar patterns prevail when looking at access to substance abuse service providers. Further, whereas white respondents in suburban Oakland County have less access to service providers than African Americans across

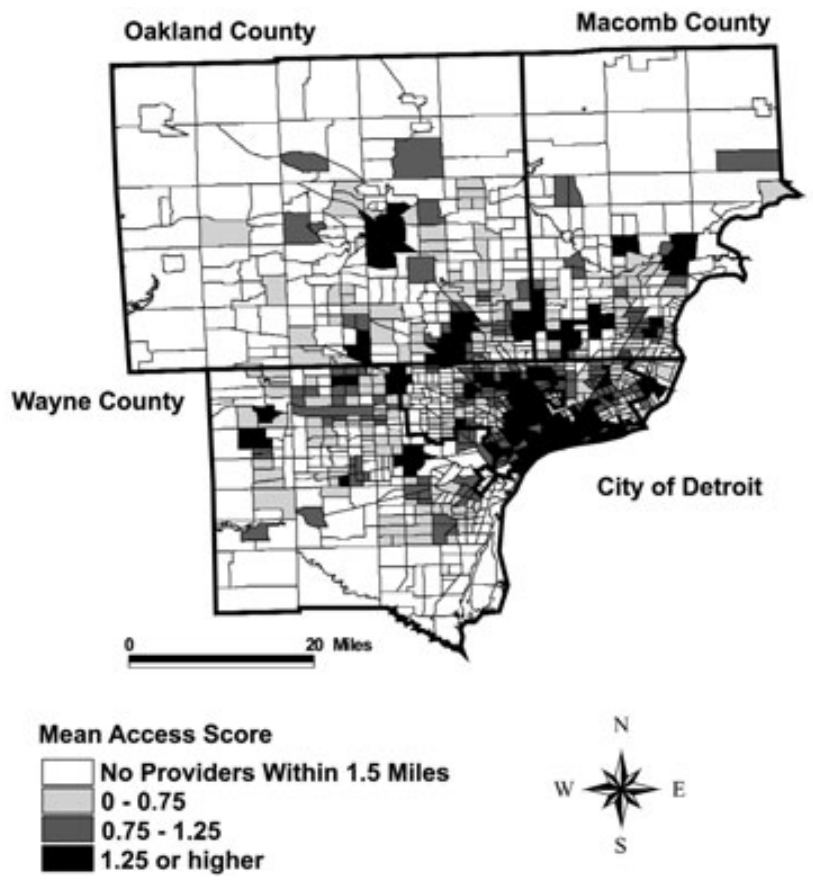

Figure 1. Spatial Accessibility of Mental Health and Substance Abuse Providers Treating Low-Income Women Within 1.5 Miles, 2000. 


\section{Proximity and Service Utilization among Welfare Recipients / 607}

all five accessibility measures, white respondents in nearby suburban Wayne County have greater access to both mental health and substance abuse service providers than African Americans.

\section{EFFECT OF ACCESS TO SERVICES ON UTILIZATION RATES}

To assess the relationship between proximity to service providers and service utilization we estimated a pair of logistic regression models, where whether MWS respondents had received any outpatient mental health treatment in the previous 12 months is the dependent variable. A respondent is classified as having received outpatient mental health treatment if she had one or more visits to a psychiatric outpatient clinic, social service agency, or private doctor or counselor's office in the twelve months prior to the survey. Receipt of outpatient mental health services is the focus, because it is the most common mental health treatment option for welfare recipients and because inpatient treatment should be less affected by spatial accessibility. The first model shows the relationship between outpatient mental health service utilization and access to outpatient mental health service providers treating low-income women at 1.5 miles; the second model considers the relationship between utilization and access to outpatient mental health service providers treating low-income women at a 3-mile radius. For each model, respondents living near a greater number of providers would be expected to be more likely to receive services, all things being equal.

Additionally, a number of measures are included to capture individual characteristics that might affect service utilization. Included are measures of race, education, age, and the presence of children under age 5 in the household. As found in other studies, African American respondents are expected to be less likely to receive services than white respondents. Younger recipients, recipients with young children, recipients without a high school degree are expected to be less likely to utilize services. Also included is whether respondents have access to an automobile, with the expectation that respondents without a car will face greater challenges in commuting to providers, thus lowering their rates of service utilization.

To control for mental health status, a dichotomous variable was included to reflect whether a respondent fell below the national mean on a widely used standardized mental health status score produced through a battery of questions in the MWS. Lower mental health status scores indicate more severe mental health problems and respondents with poor mental health status are expected to be more likely to receive services. Combining a respondent's mental health status score with survey information about the race of the respondent, creates an interaction term indicating whether a respondent is an African American below the national mean mental health status score. This interaction term will help discern whether service utilization rates for African Americans with poor mental health status are different from other respondents in the MWS. Respondents with a diagnosed mental health disorder are expected to be more likely to receive services as well, as we included a dichotomous measure to indicate whether the instruments from the MWS diagnosed a mental health disorder in the previous 12 months.

Further, the percentage of months worked and percentage of months on welfare in the previous 12 months were included to capture any work or welfare effects on service utilization. With the expectation that demand for services in neighborhoods with higher poverty rates will outpace the supply of services and thus reduce the likelihood that an individual in a high poverty neighborhood will receive services, we include the tract-level poverty rate. Finally, to control for county-level variation 
in the implementation of welfare-to-work and social service programs, dummy variables were included to reflect county of residence.

As reflected across both columns in Table 3, respondents closer to service providers are more likely to receive services, all things being equal. For instance, the coefficient for access to outpatient mental health providers treating low-income women at 1.5 miles is positive and significant (column 1), indicating that greater access to outpatient mental health service providers treating low-income women increases the likelihood of receiving outpatient mental health services. When looking at access to mental health service providers at a 3-mile radius (column 2), even a more generous notion of mental health service accessibility is positively and significantly related to service utilization in the previous 12 months. Also as expected, African Americans were less likely to use outpatient mental health services than whites. ${ }^{8}$ Respondents

Table 3. Determinants of outpatient service utilization in previous 12 months.

\begin{tabular}{|c|c|c|c|c|}
\hline \multirow[b]{2}{*}{ Respondent Characteristic } & \multicolumn{2}{|c|}{ (1) } & \multicolumn{2}{|c|}{ (2) } \\
\hline & $\beta$ & SE & $\beta$ & SE \\
\hline $\begin{array}{l}\text { Access score for mental health service } \\
\text { providers within } 1.5 \text { miles }\end{array}$ & $0.184^{\dagger}$ & 0.099 & - & - \\
\hline $\begin{array}{l}\text { Access score for mental health service } \\
\text { providers within } 3 \text { miles }\end{array}$ & - & - & $0.330 *$ & 0.170 \\
\hline African American & $-1.208^{\dagger}$ & 0.718 & $-1.178^{\dagger}$ & 0.725 \\
\hline $\begin{array}{l}\text { Mental health status score below } \\
\text { national mean }\end{array}$ & $0.913^{\dagger}$ & 0.548 & $0.915^{\dagger}$ & 0.545 \\
\hline $\begin{array}{l}\text { African American with mental health } \\
\text { status score below national mean }\end{array}$ & 0.477 & 0.808 & 0.526 & 0.811 \\
\hline Less than a high school degree & -0.390 & 0.384 & -0.440 & 0.388 \\
\hline Age 25 to 34 & 0.121 & 0.601 & 0.113 & 0.603 \\
\hline Age 35 and Up & 0.471 & 0.681 & 0.467 & 0.693 \\
\hline Children in Household Age 5 or Under & -0.554 & 0.392 & -0.555 & 0.392 \\
\hline Diagnosed for Mental Health Disorder & $1.819 * *$ & 0.499 & $1.887 * *$ & 0.484 \\
\hline Access to automobile & -0.109 & 0.389 & -0.117 & 0.386 \\
\hline $\begin{array}{l}\text { Percentage of months worked in } \\
\text { previous } 12 \text { months }\end{array}$ & -0.278 & 0.421 & -0.270 & 0.411 \\
\hline $\begin{array}{l}\text { Percentage of Months on Welfare in } \\
\text { Previous Twelve Months }\end{array}$ & 0.177 & 0.439 & 0.193 & 0.439 \\
\hline Poverty Rate in Tract & 0.134 & 1.649 & 0.283 & 1.588 \\
\hline Macomb County & 0.528 & 0.593 & 0.635 & 0.581 \\
\hline Oakland County & 0.351 & 0.579 & 0.482 & 0.558 \\
\hline Suburban Wayne County & -0.073 & 0.625 & 0.082 & 0.625 \\
\hline Constant & $-3.695 * *$ & 1.147 & $-3.997 * *$ & 1.163 \\
\hline
\end{tabular}

$\dagger-p<0.10 \quad *-p<0.05 \quad * *-p<0.01$

Note: Logistic regression models are estimated using the MWS sample survey weights; Unweighted N = 644. Mean Access to Mental Health Service Providers within 1.5 miles = 1.106; Mean Access to Mental Health Service Providers within 3 miles = 1.096.

Sources: MWS Survey; Detroit Service Provider Database.

\footnotetext{
${ }^{8}$ We estimated models that included interaction terms for access and race. These interaction terms were positive in sign, but did not approach conventional levels of statistical significance.
} 
with mental health disorders and those with mental health status scores below the national mean were more likely to receive services. ${ }^{9}$

To show the effect that access to providers has on service utilization, Table 4 contains predicted probabilities that a white and an African American respondent with a mental health status score above and below the national mean will receive outpatient mental health services under different conditions of service accessibility. Although the magnitude of the effect varies with the definition of service accessibility, access has a noticeable effect on service utilization rates. A white respondent

Table 4. Predicted probabilities of outpatient mental health service utilization among MWS respondents.

\begin{tabular}{|c|c|c|c|c|}
\hline & \multicolumn{2}{|c|}{ White Respondent } & \multicolumn{2}{|c|}{ African American Respondent } \\
\hline & $\begin{array}{c}\text { Respondent } \\
\text { Below } \\
\text { National Mean } \\
\text { on Mental } \\
\text { Health Status } \\
\text { Scale }\end{array}$ & $\begin{array}{c}\text { Respondent } \\
\text { Above } \\
\text { National Mean } \\
\text { on Mental } \\
\text { Health Status } \\
\text { Scale }\end{array}$ & $\begin{array}{c}\text { Respondent } \\
\text { Below } \\
\text { National Mean } \\
\text { on Mental } \\
\text { Health Status } \\
\text { Scale }\end{array}$ & $\begin{array}{l}\text { Respondent } \\
\text { Above } \\
\text { National Mean } \\
\text { on Mental } \\
\text { Health Status } \\
\text { Scale }\end{array}$ \\
\hline $\begin{array}{l}\text { Twice as much access to } \\
\text { outpatient mental health } \\
\text { service providers within } \\
1.5 \text { miles as the mean } \\
\text { metropolitan tract }\end{array}$ & 27.0 & 12.9 & 15.1 & 4.2 \\
\hline $\begin{array}{l}\text { Metropolitan mean } \\
\text { access to outpatient men } \\
\text { health service providers } \\
\text { within } 1.5 \text { miles }\end{array}$ & 23.5 & 11.0 & 12.9 & 3.6 \\
\hline $\begin{array}{l}\text { Twice as much access to } \\
\text { outpatient mental health } \\
\text { service providers within } \\
\text { miles as the mean } \\
\text { metropolitan tract }\end{array}$ & 27.7 & 13.3 & 16.6 & 4.5 \\
\hline $\begin{array}{l}\text { Metropolitan mean acces } \\
\text { to outpatient mental heal } \\
\text { service providers within } \\
3 \text { miles }\end{array}$ & 21.6 & 9.9 & 12.5 & 3.3 \\
\hline
\end{tabular}

Note: Predicted probabilities based on a MWS respondent who is a 25 to 34 year old head of household without a high school degree, with no children under 5 years of age, who has access to an automobile, has been on welfare assistance for half of the 12 months prior to the survey and working half of the 12 months prior to the survey, who was diagnosed with a mental health disorder, and lives in a Census tract in the City of Detroit with a 20 percent poverty rate.

Sources: MWS Survey; Detroit Service Provider Database.

${ }^{9}$ Although not reported, we estimated models with a number of other potential explanatory variables. We estimated models that used the mental health status scores as a continuous variable and achieved very similar results. We estimated models using dichotomous measures to reflect individuals with work/no welfare, welfare/no work, and a work/welfare mix-none were significant. The presence of a cohabitor was not related to service utilization. We estimated models using a measure of child care accessibility developed from a survey response about the difficulty of finding child care when working and did not get any significant impact. Because the child care measure relates to work, we thought our measure of the presence of a young child(ren) in the home better captured the effect of child-rearing responsibilities on service utilization rates. 
below the mean national mental health status score with mean access to mental health service providers at 3 miles has a predicted mental health service utilization rate about 6 percentage points lower than the same white respondent with twice as much access as the mean metropolitan tract (21.6 versus 27.7 , respectively). Note that predicted service utilization rates for whites are roughly twice as high as for African Americans, reflecting the significant racial component to service utilization among welfare recipients. For instance the top panel in Table 4 shows that, all other things being equal, an African American respondent with poor mental health status and twice the mean access to providers at 1.5 miles is about half as likely to receive services as the comparable white respondent (15.1 percent versus 27.0 percent).

\section{DISCUSSION AND CONCLUSION}

Place matters in welfare-to-work programs, because geography structures opportunity sets for low-income households. In this instance, our findings indicate that the spatial accessibility of service providers is an important determinant of service utilization among welfare recipients. Multivariate analyses suggest that when controlling for individual characteristics, respondents living closer to mental health service providers were more likely to utilize mental health services than those living further away. For example, we found individuals in areas with high levels of access to be about 30 percent more likely to utilize services than individuals in areas with mean access to service providers.

Consistent with other studies, we find that African Americans were less likely than whites to utilize support services. Holding access constant, our models suggest that African Americans with poor mental health status were nearly half as likely to use mental health services as whites with poor mental health status. Race disparities in service utilization rates are even larger between African American and white respondents with better than average mental health. Lower rates of service utilization among African Americans have been attributed by other research to cultural differences, reliance upon family, and care-seeking only in the most severe or crisisoriented settings (Alvidrez, 1999; Snowden, 1999; Swartz et al., 1998). Nevertheless, the striking racial differences in service utilization found here strongly suggest that scholars should devote more attention to race disparities in service utilization rates.

The importance of spatial proximity to social service providers suggests that program managers should seek strategies to enhance service utilization rates by mitigating the effects of distance. Transportation assistance or on-site child care may reduce the burden of commutes to service providers. Improved outreach and marketing activities may provide recipients with information about available services and area social service providers. Increasing involvement with or attachment to primary community programs or organizations (e.g., after school programs, community centers, parental support groups) may also help low-income populations overcome informational and cultural barriers to receiving care from more specialized service providers (Richman and Stagner, 1986; Wynn, 1995).

As a significant percentage of social welfare expenditures continue to be targeted at governmental and non-governmental delivery of social services, understanding which factors shape service utilization among low-income populations becomes increasingly important. For instance, it seems likely that the administrative features of a particular provider will shape the impact that proximity to that provider has on utilization rates. Additional research should seek to create distance-weighted measures of access, therefore, which take into account factors such as hours of operation and number of frontline service staff. Such data would add precision to our 
understanding of how spatial proximity and characteristics of service providers affect patterns of service to utilization. Further, while we are able to make some assessments about the stock and flow of service providers, our data is limited in that we cannot accurately assess the supply of services and the demand for services when calculating our access measures. Data that can track the changing spatial patterns of demand for services and the availability of services would be able to provide more accurate estimates of the impact of service access upon utilization rates, as well as discuss how service accessibility may be shifting over time.

This project was supported in part by a grant from the U.S. Department of Health and Human Services, Office of the Assistant Secretary for Planning and Evaluation, grant number 00ASPE356A; and by the National Institute of Mental Health, grant number R24MH57943-01. The opinions and conclusions expressed herein are solely those of the authors and should not be construed as representing the opinions of any agency of the federal government.

SCOTT W. ALLARD is Assistant Professor of Political Science and Public Policy at Brown University.

RICHARD M. TOLMAN is a Professor in the School of Social Work, University of Michigan.

DANIEL ROSEN is Assistant Professor in the School of Social Work, University of Pittsburgh.

\section{REFERENCES}

Allard, S.W. (2002). The urban geography of welfare reform: spatial patterns of caseload dynamics in Detroit. Social Science Quarterly, 83(4), 1044-1062.

Allard, S.W., \& Danziger, S. (2003). Proximity and opportunity: how residence and race affect welfare recipients. Housing Policy Debate, 13(4), 675-700.

Alvidrez, J. (1999). Ethnic variations in mental health attitudes and service use among lowincome African American, Latina, and European American young women. Community Mental Health Journal, 35(6), 515-530.

Bass, L., \& Jackson, M.S. (1997). A study of drug abusing African American pregnant women. Journal of Drug Issues, 27(3), 659-671.

Bhugra, D. (2002). Ethnic factors and service utilization. Current Opinion in Psychiatry, 15(2), 201-204.

Comfort, M., Loverro, J., \& Kaltenbach, K. (2000). A search for strategies to engage women in substance abuse treatment. Social Work in Health Care, 31(4), 59-70.

Danziger, S., Corcoran, M., Danziger, S., Heflin, C., Kalil, A., Levine, J., Rosen, D., Seefeldt, K., Siefert, K., \& Tolman, R. (2000). Barriers to the employment of welfare recipients. In R. Cherry \& W. Rodgers (Eds.), The impact of tight labor markets on black employment problems. New York: Russell Sage.

Derr, M. K., Hill, H., \& Pavetti, L. (2000). Addressing mental health problems among tanf recipients: a guide for program administrators. Princeton, NJ: Mathematica Policy Research, Inc.

GAO [U.S. General Accounting Office]. (2000). Homelessness: barriers to using mainstream programs, GAO/RCED-00-184. Washington, DC: Government Printing Office.

GAO [U.S. General Accounting Office]. (2001). Welfare reform: moving hard-to-employ recipients into the workforce, GAO-01-368. Washington, DC: Government Printing Office. 


\section{2 / Proximity and Service Utilization among Welfare Recipients}

GAO [U.S. General Accounting Office]. (2002a). Welfare reform: states provide TANF-funded services to many low-income families who do not receive cash assistance, GAO-02-564. Washington, DC: Government Printing Office.

GAO [U.S. General Accounting Office]. (2002b). Human services integration: results of a GAO cosponsored conference on modernizing information systems, GAO-02-121. Washington, DC: Government Printing Office.

Goodman, D.C., Fisher, E. Stukel, T., \& Chang, C. (1997). The distance to community medical care and the likelihood of hospitalization: is closer always better? American Journal of Public Health, 87 (7), 1144-1150.

HHS [U.S. Department of Health and Human Services]. (2002). State strategies for working with hard-to-employ TANF recipients. Available at: <http://oig.hhs.gov/oei/reports/oei-0200-00630.pdf>; accessed May 8, 2003.

Howard, K.I., Thomas, C.A., Lyons, J.S., Vessey, J.T., Lueger, R.J., \& Saunders, S.M. (1996). Patterns of mental health service utilization. Archives of General Psychiatry, 53, 696-703.

Howell E.M., \& Chasnoff, I.J. (1999). Perinatal substance abuse treatment: findings from focus groups with clients and providers. Journal of Substance Abuse Treatment, 17(1/2), 139-148.

Jayakody, R., Danziger, S., \& Pollack, H. (2000). Welfare reform, substance abuse, and mental health. Journal of Health Politics, Policy and Law, 25(4), 623-651.

Jayakody, R., \& Stauffer, D. (2000). Mental health problems among single mothers: implications for work and welfare reform. Journal of Social Issues, 56:617-634.

Kessler R.C., Zhao, S.Y., Katz, S.J., Kouzis, A.C., Frank, R.G., Edlund, M., \& Leaf, P. (1999). Past-year use of outpatient services for psychiatric problems in the national comorbidity survey. American Journal of Psychiatry, 156(1), 115-123.

Klerman, J.A., Zellman, G., Chun, T.J., Humphrey, N., Reardon, E., Farley, D., Ebener, P.A., \& Steinberg, P. (2000). Welfare reform in California: state and county implementation of CalWorks in the second year, MR-1177-CDSS. Santa Monica, CA RAND Corporation. Available at: <http://www.rand.org/publications/MR/MR1177>; Accessed May 8, 2003.

Melfi, C.A., Croghan, T.W., \& Hanna, M.P. (1999). Access to treatment for depression in a medicaid population. Journal of Health Care for the Poor and Underserved, 10, 201-215.

Metsch, L.R., McCoy, C.B., Miller, M., McAnany, H., \& Pereyra, M. (1999). Moving substanceabusing women from welfare to work. Journal of Public Health Policy, 20, 36-55.

Nelson-Zlupko, L., Kauffman, E., \& Dore, M. (1995). Gender differences in drug addiction and treatment: implications for social work intervention with substance abusing women. Social Work, 40(1), 45-54.

Nemet, G.F., \& Bailey, A.J. (2000). Distance and health care utilization among the rural elderly. Social Science and Medicine, 50(9), 1197-1208.

Nightingale, D.S. (2001). Program structure and service delivery in eleven welfare-to-work grant programs. Washington, DC: Urban Institute.

Richman, H., \& Stagner, M. (1986). Help-Seeking and the use of social service providers by welfare families in Chicago. Working Paper. Chapin Hall Center for Children at the University of Chicago.

SAMHSA [Substance Abuse and Mental Health Services Administration]. (1999). Mental health: a report of the Surgeon General-executive summary. Washington, DC: Government Printing Office.

Sherbourne, C.D., Dwight-Johnson, M., \& Klap, R. (2001). Psychological distress, unmet need, and barriers to mental health care for women. Women's Health Issues, 11(3), 231-243.

Snowden, L.R. (1999). African American service use for mental health problems. Journal of Community Psychology, 27(3), 303-313.

Swartz, M.S., Wagner, H.R., Swanson, J.W., Burns, B.J., George, L.K., \& Padgett, D.K. (1998). 
Administrative update: utilization of services. Community Mental Health Journal, 34(2), 133-144.

University of Wisconsin. (1999). Support service utilization among Head Start families in Wisconsin. Milwaukee: University of Wisconsin, Center for Economic Development. Available at: <http://www.uwm.edu/Dept/CED/reports/headstart.pdf>; accessed May 8, 2003.

Ware J.E., Kosinski, M., \& Keller, S.D. (1996). A 12-item short-form health survey: construction of scales and preliminary tests of reliability and validity. Medical Care, 34(3), 220-233.

Whaley, A.L. (2001). Cultural mistrust and mental health services for African Americans: a review and meta-analysis. Counseling Psychologist, 29(4), 513-531.

Williams, J.H., Pierce, R., Young, N.S., \& VanDorn, R.A. (2001). Service utilization in highcrime communities: consumer views on supports and barriers. Families in Society, 82(4), 409-417.

Wittchen, H.U. (1994). Reliability and validity studies of the WHO-composite International Diagnostic Interview (CIDI): a critical review. Journal of Psychiatric Research, 28(1), 57-84.

Wobie, K., Eyler, F.D., Conlon, M., Clarke, L., \& Behnke, M. (1997). Women and children in residential treatment: outcomes for mothers and their infants. Journal of Drug Issues, 27(3), 585-606.

Wynn, J.R. (1995). Enhancing social services for children, youth, and families. Public Welfare, Fall, 12-23.

Zedlewski, S.R., \& Alderson, D.W. (2001). Before and after reform: how have families on welfare changed? series B, no. B-32. Washington, DC: Urban Institute. 